\title{
The Association between Eating Habits and Body Mass Index among Nursing Students
}

\author{
Manal Hamed Mahmoud ${ }^{1}$, Amal Said Taha ${ }^{2}$ \\ ${ }^{l}$ (Assistant Professor of Medical-Surgical Nursing, Faculty of Nursing, Benha University, Egypt) \\ ${ }^{2}$ (Lecturer of Medical-Surgical Nursing, Faculty of Nursing, Benha University, Egypt)
}

\begin{abstract}
Background: Eating habits among university students are changing while they are transferring from home environment. Despite the fact that unhealthy eating habits can affect negatively on their health. Aim of the study: Was to explore the association between eating habits and Body Mass Index (BMI) among nursing students. Methods: A descriptive correlation design utilized to conduct this study. This study carried out at Faculty of Nursing, Benha University. Subjects: The study included 125 (male and female) second year nursing students. Tools of the study: Two tools used in this study; 1) Demographic data sheet: included demographic characteristics of the students and their anthropometric measurements; 2) Eating habits questionnaire: contained information about healthy and unhealthy eating habits. Results: revealed that there is no significant statistical correlation between eating habits and BMI among students $(P>0.05)$.Conclusion and recommendations: Despite being highly educated students, the majority of students did not have healthy eating habits. In addition, there was no association between eating habits and BMI among the study group. Educational programs can be provided for university students to increase their awareness about healthy food and healthy eating habit. Moreover further study is recommended to explore factors affecting eating habits among them.
\end{abstract}

Key Words: Eating habits, Body Mass Index, nursing students.

\section{Introduction}

Health is a basic and active meaning in all people's habitual lives. It is influenced by habits, circumstances, attitudes, believes as well as social and physical environment. Health is a combination within the brain, body, and spirit, which is deemed distinctive to each individual [1].The industrialization, urbanization, financial advancement and market inclusiveness have led to lifestyle change of the worldwide population. As a result, the dietary habits have been changing during the last decades, described by an increase of fat intake, commonly in saturated fat, beside a decline in cereals, fruits, legumes and vegetables eating [2]. Cultural factors such as dietetic practice, attitude towards food are varying which finally affects the impact of eating habits [3]. Young adults are more linked with the beginning of puberty and cognitive maturity and consequently require additional nutrients for appropriate development. They are also allied with recurrent habit of skipping meals [4].Unhealthy, unbalanced eating habits and diseases induced by this age group were located in the first priority [5]. Eating habits and practices detected in young adults may have harmful effect on their health. An example is breakfast, which has been recognized to have essential responsibility in brain development of young adults, while, these age group are usually linked with the maximal rate in skipping breakfast [6]. A high-fat diet, particularly one rich in Trans fats, which has negatively influence individual health which becoming a risk factor for chronic diseases [7]. This category of habits for the young adults can lead to increase body weight in the future, and are expected to turn into regular habits for them and their families [8]. Becoming a university student has a forceful impact on the lifestyle of persons and may frequently result in unhealthy eating habits [9]. Poor eating habits are a significant public health concern that has great health and cost-effective intention. Many food preferences are recognized early, but since people make more and more self-regulating eating decisions as they move through puberty, the transition to independent living during the university days is an important event[10].Nearly all of the university students seem to be affected by this nutrition transition [11]. Studies from developed countries have revealed that young adults leaving their family and living far from home to joined college experience, where there are several health-related behavioral changes, involving the acquiring of unhealthy dietary habits [12]. Added to this, skipping meals may also turn into more frequent [13]. Studies in the Middle East confirm that adolescents and adults eating habits are negatively being influenced by the changing environmental-feature leading to frightening rates of overweight and obesity and elevated metabolic risk factors cause diabetes, hypertension, and other chronic disorders[14]. The adverse health consequences that may result from excessive intake of fizzy drinks, sweet drinks and fast foods utilization; insufficient intake of fruits, vegetables, whole grain foods, dairy products and other and rising obesity rates signify a need to recommence the diet and lifestyle distinctiveness of this age group[15]. Nurses play a vital role in healthcare 
whether they are working at the patient bedside, caring for clients in a physician office, or administer care and teaching as part of public health. They are care providers, life saver, cheer leaders, confidants, trusted resources, and so much more. This is why it is so significant for nurses to take care of themselves as well. Nurses can gain from optimal nutrition to help them conduct healthy life. When healthcare professionals, such as nurses, concern for their personal health, it is realistic to believe that this will assist them to improve care for patients. Good nutrition is an effortless and central part of healthy habit that can be simply integrated into the daily practice of a nurse. For example, healthy food choices may assist to control stressors, keep weight at a healthy level, and enhance energy levels [16]. Adding to the significance of nourishment for the high-quality health of nurses, it is often nurses who offer nutrition assessment and/or education to patients. In this responsibility, they provide knowledge about nutrition to patients, but also act as role models. Research has verified that nurses have concerns about both supplying compound nutritional information to patients and patient perceptions of their body image[17] and [18]. In order to know the eating habits of students, it becomes compulsory to assess the nutritional status of students taking into account the different foods that themselves choose to eat[19]. Moreover, BMI is the most widely used and simplest anthropometric index for assessing the nutritional status of children and adults while it can be used to categorize those who may be overweight, underweight, normal weight and obese at risk, based on age and sex [20].

\section{Significance of the study:}

With the conversion from secondary school to university, as autonomous increases, students are continually challenged to create healthy food choices [21]. Such evolution into young adulthood is commonly a period of unhealthy lifestyle where young people could suppose lifelong health behavior habits [22] and [23]. Eating habits are a main concern amongst university students particularly due to the transition from home atmosphere where parents decide what to be eaten, to new environments where they or their peers select the diet. Eating habits are considered determinants of health status and has been related to death from Noncommunicable illness [24]. In this circumstance, university students signify an attractive type of consumer because on the one hand, they affected by the food utilization choices of their families, while on the other hand, they are starting to make self-determining food selections [25]. College students are showing unhealthy eating habits leading to gain of body weight, and make their self-regulating food choices, sometimes based on price of food and accessibility of fast food[26]. Moreover, a study carried out by [27], concluded that, insufficient and unbalanced diet observed in the students reduced the attention spans and perceptions and caused a drop in their performance together with learning difficulties and behavioral disorders. Additionally, obesity is the chief public health concerns that significantly expanding tread worldwide. Numerous factors such as unhealthy lifestyle and reduced physical fitness may associate with obesity in young adults [28]. National and population-based surveys have discovered that young people usually fail to fulfill nutritional recommendations for overall dietary status and for intakes of particular nutrient [29]. For the above mentioned reasons the researchers of the current study attempted to explore the eating habits of nursing students and it's relation to their body mass index.

Aim of the study:

The aim of this study is to explore the association between eating habits and body mass index among nursing students

\section{Research questions:}

-Is there any relation between eating habits and body mass index among nursing students?

-What is the effect of gender on eating habits and BMI among nursing students?

\section{Subject And Methods}

Research Design:

A descriptive correlation design utilized in this study

\section{Setting:}

This study carried out at Faculty of Nursing, Benha University.

\section{Subjects:}

The study involved 125 second year nursing students (male and female). The study subjects comprised $30 \%$ of the total number of the second year nursing students (415) and selected randomly by using the simple random sampling technique. 
Tools of the study:

First tool: demographic data sheet:

Included information about the demographic characteristics of the studied subjects such as student's age, sex and their anthropometric measurements which involved data about the students' weight, height and Body Mass Index (BMI). IT developed by the investigators, and body mass index(BMI) calculation adapted from [30].

Second tool: Eating habits questionnaire: It is a likert like scale with five options that representing how often participants practiced eating habits with five options; repeatedly, often, occasionally, seldom and never with scores ranged from 1 to 5 to each item. It adapted from [31], it translated into Arabic language and required adjustment done. It consisted of four parts:

Part I: Unhealthy food habits: Included 13 item of unhealthy eating habits that may be followed by the study subjects, with scores ranged from 13 to 65 scores.

Part II: Eating healthy food: Comprised 9 items of healthy food that eaten by participants with scores ranged from 9 to 45 scores.

Part III: Following healthy eating habits: Contained 8 item of healthy eating habits that may be followed by the study group, with scores ranged from 8 to 40 scores.

Part IV: Planning for eating healthy food: Involved 7 element of healthy food that may be planned by the study group with marks ranged from 7 to 35 scores. The total scores of eating habits questionnaire are $37 x=185$ scores. Earned scores of the study participants are classified as the following:

- $\quad$ Scores ranged from 37 to 86 indicated unhealthy eating habits

- Scores ranged from 87 to 135 indicated neutral eating habits (means that healthy eating habits are equal to unhealthy eating habits).

- Scores ranged from 136 to 185 indicated healthy eating habits

Methods:

The study conducted according to the following Steps:

Official permissions obtained from the dean of the faculty of nursing, Benha University to perform the study after explaining its purpose.

\section{Content validity:}

The second tool tested for content validity by a jury of five expertise in the medical-surgical nursing.

\section{Tool reliability:}

The second tool tested for its reliability using Cronbach's Alpha coefficient test and proved to be

Pilot study: reliable $(\alpha=(0.7)$.

A pilot study was carried out on randomly selected $10 \%$ of students who were not incorporated in the actual study. The purpose of the pilot study was to test the applicability of the tools and assess the time needed to complete the tools

\section{Data collection:}

The demographic data of the students and their anthropometric measurements filled by the investigators. Measurement of participants' body weight performed using a decimal scale in kilograms, after the removal of shoes and excess clothing. The measurement of participants' height obtained using a mounted metal centimeter ruler without shoes. The body mass index (BMI) calculated according to [30], as ratio between weight in kilograms and height in meters squared and results recorded as $\left(\mathrm{kg} / \mathrm{m}^{2}\right)$. Participants categorized according to their Body Mass Index as the following:

Under weight: BMI is lower than $18.5 \mathrm{~kg} / \mathrm{m}^{2}$

Normal weight: BMI ranged from 18.5 to $24.9 \mathrm{~kg} / \mathrm{m}^{2}$

Over weight: BMI ranged from 25 to $29.9 \mathrm{~kg} / \mathrm{m}^{2}$

Obese: BMI is more than $30 \mathrm{~kg} / \mathrm{m}^{2}$

Eating habits questionnaire handed to the participants to be accomplished after full explanation about how to fill and the importance of honestly response. The students' filled the study tool in the presence a of the researcher to ensure that all information incorporated in the questionnaire understood and finished. At this time each student interviewed individually for about 30 minutes. Data collected 3 days a week, 3-4 students were interviewed per day, for a period of 3 months started on October 2016 to the end of December 2016 


\section{Ethical considerations:}

The research approved by the ethical committee at the Faculty of Nursing, Benha university. At this time, informed oral consent gained from the study subjects after clarification of the reason and significance of the study, and comforting them about the secrecy of any obtained information. Moreover ambiguity of the study subjects was assured.

\section{Statistical analysis:}

The Statistical Package for Social Sciences (SPSS) version 18 was used for data analysis. Descriptive statistics and correlation coefficients were used to answer the research questions. Descriptive statistics (frequency, percentage, arithmetic mean and standard deviation) were used to describe the subject characteristics, including socio-demographic data and eating habits among them. Independent T-test was used to examine the differences between male and female students regarding their eating habits. Fisher Exact Test (FET) was used to examine the relations between variables if there is small expected value. The $\mathrm{p}$-value $>0.05$ indicates non-significant results.

\section{Results}

Table (1) reveals that the majority of the participants were female $(66.4 \%)$ and had normal weight $(60 \%)$, in addition, their mean weight and height were $62.47 \pm 11.30$ and $162.08 \pm 9.45$ respectively.

Figure (1) indicates that the majority of male and female students have normal weight $(54.80 \% \& 62.70 \%$ respectively) and there is no significant statistical relation between students gender and their $\mathrm{BMI}(\mathrm{P}>0.05)$.

Table (2) represents that, the majority of the students repeatedly, often and occasionally eat fast food as well as fatty food(22.4\%, 19.2\% \& 29.6\%), also eat snakes between meals(14.4\%, 13.6\% \& 35.2\%). A lot of student were repeatedly, often and occasionally eat dessert (18.4\%, $32 \% \& 24 \%)$, as well drink tea after meals $(26.4 \%$, $8.8 \% \& 15.2 \%)$. While most of them were never and rarely drink coffee after meals $(53.6 \% \& 24.8 \%)$ and drink fizzy with meals $(29.6 \% \& 28.8 \%)$.

Table (3) shows that majority of the students were never, rarely and occasionally eat breakfast daily (12\%, $16.8 \% \& 26.4 \%)$, as well eat three meals every day $(7.2 \%, 19.2 \% \& 34.4 \%)$. In addition, more than half of them were never, rarely and occasionally eat or drink more dairy foods and whole grain foods $(10.4 \%, 9.6 \% \& 32 \%)$. While the majority of them were repeatedly and often eat more fruits $(35.2 \% \& 32.8 \%)$, and more vegetables $(24.8 \%$ \& $32.0 \%)$,

Table (4) demonstrates that, nearly half of the students were never and rarely keep track of food elements in their meals $(22.4 \% \& 24.8)$, keep track of servings they eat daily from dairy foods $(25.6 \% \& 22.4 \%)$ as well as keep track of servings they eat daily from whole grain foods $(22.4 \% \& 26.4 \%)$. On the other hand, nearly half of them were repeatedly and often remind themselves to drink fewer sodas or sugared drink $(27.2 \% \& 16.8 \%)$.

Table (5) reveals that, the majority of students were never and rarely plan to drink or eat 3 servings of dairy foods daily $(37.6 \% \& 31.2 \%)$, plan to eat more whole grain foods $(30.4 \% \& 33.6 \%)$, plan to eat 5 servings of fruits and vegetables daily $(32.8 \% \& 24.8 \%)$. While, more than one third of students were repeatedly and often plan to eat three meals daily $(25.6 \% \& 15.2 \%)$.

Table (6) shows that there is no significant statistical differences between male and female students regarding their eating habits.

Table (7) indicates that there is no significant statistical correlation between eating habits and body mass index (BMI) among the students in this study.

Figure (2) reveals that the majority of the students in the current study ( $83.1 \%$ of females and $73.8 \%$ of males) had neutral eating habits and there is no significant statistical difference between students' gender and their eating habits. 
Table (1): Demographic characteristics of the study subjects $(n=125)$

\begin{tabular}{lll}
\hline Demographic characteristics & No & \% \\
\hline Sex & & \\
$\quad$ Male & 42 & 33.6 \\
$-\quad$ Female & 83 & 66.4 \\
\hline BMI Categories & & \\
$-\quad$ Under weight & 75 & 7.2 \\
$-\quad$ Normal weight & 30 & 60.0 \\
$-\quad$ Over weight & 11 & 24.0 \\
$-\quad$ Obese & & 8.8 \\
\hline Mean \pm SD & $62.47 \pm 11.30$ & \\
Weight Mean \pm SD & $162.08 \pm 9.45$ & \\
Height $\quad$ Mean \pm SD &
\end{tabular}

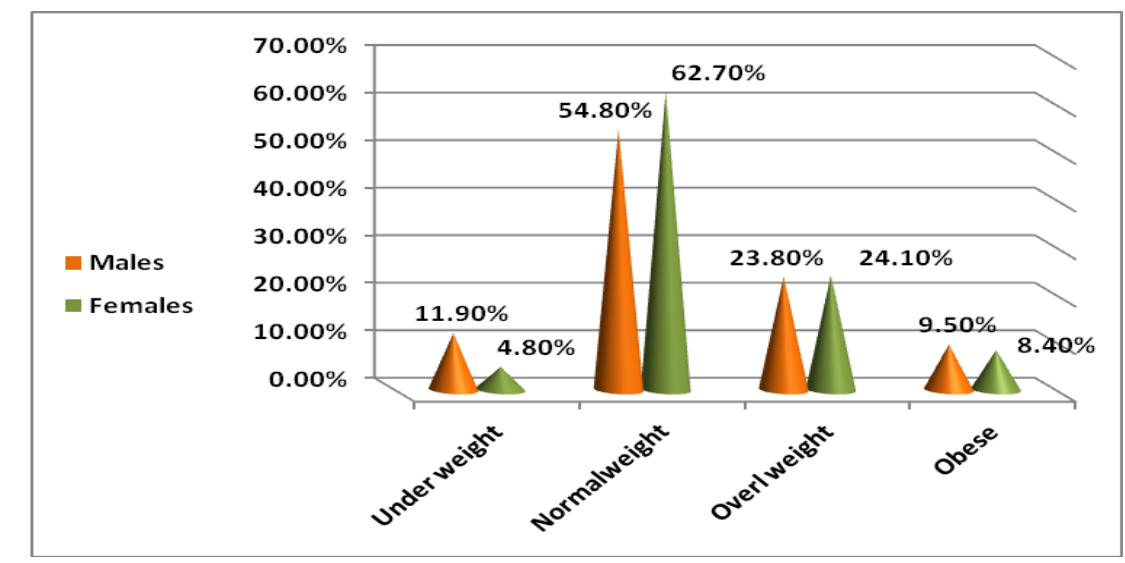

FET $=2.364 \quad$ P $>0.05$

Fig. (1): Relation between students' gender and their BMI ( $n=125)$

Table (2): Percent distribution of the study subjects according to their unhealthy eating habits $(n=125)$

\begin{tabular}{|c|c|c|c|c|c|c|c|c|c|c|}
\hline \multirow[t]{2}{*}{ Unhealthy eating habits } & \multicolumn{2}{|c|}{$\begin{array}{c}\text { Repeatedly } \\
\text { (1) }\end{array}$} & \multicolumn{2}{|c|}{$\begin{array}{l}\text { Often } \\
(2)\end{array}$} & \multicolumn{2}{|c|}{$\begin{array}{l}\text { Occasionally } \\
\text { (3) }\end{array}$} & \multicolumn{2}{|c|}{$\begin{array}{l}\text { Rarely } \\
\text { (4) }\end{array}$} & \multicolumn{2}{|c|}{$\begin{array}{l}\text { Never } \\
\text { (5) }\end{array}$} \\
\hline & No & $\%$ & No & $\%$ & No & $\%$ & No & $\%$ & No & $\%$ \\
\hline - Eat fast food & 28 & 22.4 & 24 & 19.2 & 37 & 29.6 & 31 & 24.8 & 5.0 & 4.0 \\
\hline - Eat fatty food & 28 & 22.4 & 24 & 19.2 & 37 & 29.6 & 31 & 24.8 & 5.0 & 4.0 \\
\hline - Eat frying food & 1.0 & 0.8 & 17 & 13.6 & 40 & 32.0 & 50 & 40.0 & 17 & 13.6 \\
\hline - Eat dessert. & 23 & 18.4 & 40 & 32.0 & 30 & 24.0 & 28 & 22.4 & 4.0 & 3.2 \\
\hline - Eat food from restaurants. & 14 & 11.2 & 27 & 21.6 & 37 & 29.6 & 35 & 28.0 & 12 & 9.6 \\
\hline - Drink fizzy with meals. & 14 & 11.2 & 12 & 9.6 & 26 & 20.8 & 36 & 28.8 & 37 & 29.6 \\
\hline - Drink tea after meals. & 33 & 26.4 & 11 & 8.8 & 19 & 15.2 & 22 & 17.6 & 40 & 32.0 \\
\hline - Drink coffee after meals. & 7.0 & 5.6 & 9.0 & 7.2 & 11 & 8.8 & 31 & 24.8 & 67 & 53.6 \\
\hline - Eat snakes between meals. & 18 & 14.4 & 17 & 13.6 & 44 & 35.2 & 26 & 20.8 & 20 & 16.0 \\
\hline - Eat salty food. & 25 & 20.0 & 30 & 24.0 & 39 & 31.2 & 25 & 20.0 & 6.0 & 4.8 \\
\hline - Eat canned food. & 17 & 13.6 & 14 & 11.2 & 41 & 32.8 & 45 & 36.0 & 8.0 & 6.4 \\
\hline - Eat under cocked food. & 3.0 & 2.4 & 8.0 & 6.4 & 18 & 14.4 & 28 & 22.4 & 68 & 54.4 \\
\hline - Eat spicy food. & 32 & 25.6 & 32 & 25.6 & 21 & 16.8 & 24 & 19.2 & 16 & 12.8 \\
\hline
\end{tabular}


Table (3): Percent distribution of the study subjects according to their eating healthy foods $(n=125)$

\begin{tabular}{|c|c|c|c|c|c|c|c|c|c|c|}
\hline \multirow[t]{2}{*}{ Eating healthy foods: } & \multicolumn{2}{|c|}{$\begin{array}{r}\text { Never } \\
\text { (1) }\end{array}$} & \multicolumn{2}{|c|}{$\begin{array}{l}\text { Rarely } \\
\text { (2) }\end{array}$} & \multicolumn{2}{|c|}{$\begin{array}{l}\text { Occasionally } \\
\text { (3) }\end{array}$} & \multicolumn{2}{|c|}{$\begin{array}{r}\text { Often } \\
(4)\end{array}$} & \multicolumn{2}{|c|}{$\begin{array}{l}\text { Repeatedly } \\
\text { (5) }\end{array}$} \\
\hline & No & $\%$ & No & $\%$ & No & $\%$ & No & $\%$ & No & $\%$ \\
\hline - Eat breakfast daily. & 15 & 12.0 & 21 & 16.8 & 33 & 26.4 & 27 & 21.6 & 29 & 23.2 \\
\hline - Eat more vegetables. & 1 & 0.8 & 20 & 16.0 & 33 & 26.4 & 40 & 32.0 & 31 & 24.8 \\
\hline - Eat more fruits. & 0 & 0.0 & 6 & 4.8 & 34 & 27.2 & 41 & 32.8 & 44 & 35.2 \\
\hline - Eat or drink more dairy foods. & 13 & 10.4 & 12 & 9.6 & 40 & 32.0 & 39 & 31.2 & 21 & 16.8 \\
\hline - Eat more whole grain foods. & 13 & 10.4 & 12 & 9.6 & 40 & 32.0 & 39 & 31.2 & 21 & 16.8 \\
\hline - Eat low-fat salad dressing. & 4 & 3.2 & 23 & 18.4 & 48 & 38.4 & 34 & 27.2 & 16 & 12.8 \\
\hline - Eat breakfast purposefully . & 8 & 6.4 & 12 & 9.6 & 40 & 32.0 & 35 & 28.0 & 30 & 24.0 \\
\hline - Eat three meals every day. & 9 & 7.2 & 24 & 19.2 & 43 & 34.4 & 34 & 27.2 & 15 & 12.0 \\
\hline - Meals contain all food elements & 28 & 22.4 & 25 & 20.0 & 37 & 29.6 & 21 & 16.8 & 14 & 11.2 \\
\hline
\end{tabular}

Table (4): Percent distribution of the study subjects according to following healthy eating habits $(\mathrm{n}=125)$

\section{Following healthy eating habits}

Keep track of how many meal you eat.

- Keep track of food elements in your meals.

- Remind yourself that eating breakfast is healthy.

- Remind yourself to drink fewer sodas or sugared drinks.

- Keep track of servings eaten daily from fruits and vegetables 26

- Keep track of servings you eat daily from dairy foods 32

- Keep track of servings you eat daily from whole grain foods. 28

- Keep track of your daily drink from dizzy or sugared drinks. 23

Never Rarely

(1)

(2)
No $\% \quad$ No

$\begin{array}{lll}28 & 22.4 & 25\end{array}$

$\begin{array}{lll}28 & 22.4 & 31 \\ 19 & 15.2 & 23\end{array}$

Occasionally

(3)

$$
\text { \% No \% }
$$

(4) $\quad(5)$

Table (5): Percent distribution of the study subjects according to planning for eating healthy food $(\mathrm{n}=125)$

\begin{tabular}{|c|c|c|c|c|c|c|c|c|c|c|}
\hline \multirow[t]{2}{*}{ Planning for eating healthy food } & \multicolumn{2}{|c|}{$\begin{array}{r}\text { Never } \\
\text { (1) }\end{array}$} & \multicolumn{2}{|c|}{$\begin{array}{l}\text { Rarely } \\
\text { (2) }\end{array}$} & \multicolumn{2}{|c|}{$\begin{array}{l}\text { Occasionally } \\
\text { (3) }\end{array}$} & \multicolumn{2}{|c|}{$\begin{array}{l}\text { Often } \\
(4)\end{array}$} & \multicolumn{2}{|c|}{$\begin{array}{l}\text { Repeatedly } \\
\text { (5) }\end{array}$} \\
\hline & No & $\%$ & No & $\%$ & No & $\%$ & No & $\%$ & No & $\%$ \\
\hline Plan to eat breakfast. & 21 & 16.8 & 29 & 23.2 & 27 & 21.6 & 31 & 24.8 & 17 & 13.6 \\
\hline Plan to eat 5 servings of fruits and vegetables daily. & 41 & 32.8 & 31 & 24.8 & 35 & 28.0 & 14 & 11.2 & 4 & 3.2 \\
\hline Plan to drink or eat 3 servings of dairy foods daily. & 47 & 37.6 & 39 & 31.2 & 28 & 22.4 & 9 & 7.2 & 2 & 1.6 \\
\hline Plan to eat more whole grain foods. & 38 & 30.4 & 42 & 33.6 & 28 & 22.4 & 16 & 12.8 & 1 & .8 \\
\hline Plan to drink fewer sodas or sugared drinks & 26 & 20.8 & 20 & 16.0 & 23 & 18.4 & 33 & 26.4 & 23 & 18.4 \\
\hline Plan to eat three meals daily. & 21 & 16.8 & 16 & 12.8 & 37 & 29.6 & 19 & 15.2 & 32 & 25.6 \\
\hline Plan to eat meals with all food elements. & 23 & 18.4 & 25 & 20.0 & 33 & 26.4 & 28 & 22.4 & 16 & 12.8 \\
\hline
\end{tabular}

Table (6): Gender differences among students regarding their eating habits $(n=125)$

\begin{tabular}{lccccc}
\hline Item & $\begin{array}{c}\text { Maximum } \\
\text { score }\end{array}$ & $\begin{array}{c}\text { Male } \\
\text { Students }\end{array}$ & $\begin{array}{c}\text { Female } \\
\text { students }\end{array}$ & T & P \\
\hline - Unhealthy eating habits & 65 & $41.35 \pm 7.31$ & $40.90 \pm 6.34$ & 0.358 & $>0.05$ \\
\hline - Eating healthy foods & 45 & $28.95 \pm 6.41$ & $30.44 \pm 6.20$ & 1.257 & $>0.05$ \\
\hline - Following healthy eating habits & 40 & $23.00 \pm 6.44$ & $21.97 \pm 7.12$ & 0.783 & $>0.05$ \\
\hline - Planning for eating healthy food & 35 & $19.16 \pm 6.30$ & $18.36 \pm 6.00$ & 0.696 & $>0.05$ \\
\hline - Total score & 185 & $112.47 \pm 21.23$ & $111.68 \pm 17.23$ & 0.223 & $>0.05$ \\
\hline - $\quad$ The test used is independent t test & & & & &
\end{tabular}

Table (7): Correlation coefficient between students' eating habits and their BMI $(n=125)$

\begin{tabular}{|c|c|c|}
\hline \multirow[t]{2}{*}{ Students' eating habits } & \multicolumn{2}{|l|}{ BMI } \\
\hline & $\mathbf{r}$ & $\mathbf{P}$ \\
\hline - $\quad$ Unhealthy eating habits & 0.081 & $>0.05$ \\
\hline Eating healthy foods & 0.027 & $>0.05$ \\
\hline Following healthy eating habits & 0.007 & $>0.05$ \\
\hline - $\quad$ Planning for eating healthy food & 0.015 & $>0.05$ \\
\hline$-\quad$ Total score & 0.122 & $>0.05$ \\
\hline
\end{tabular}


The Association between Eating Habits and Body Mass Index among Nursing Students

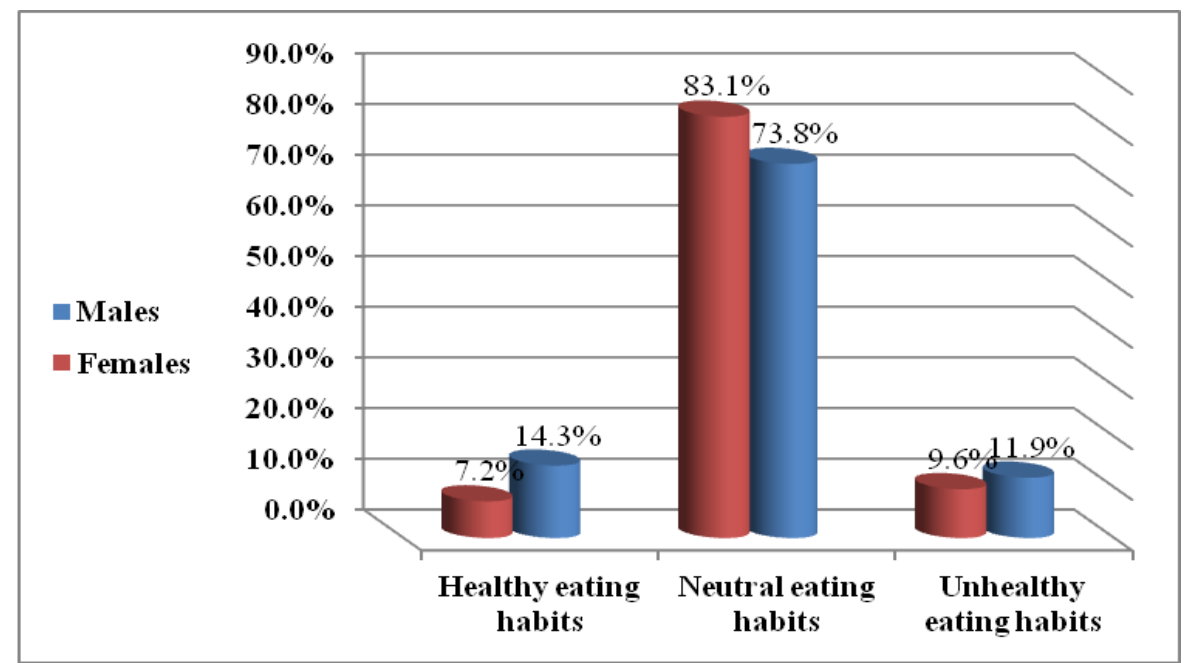

FET $=2.023 \quad$ P>0.05

Fig. (2): Distribution of the study participants according to their eating habits

\section{Discussion}

The present study aimed to explore the association between eating habits and body mass index among nursing students. Discussion the findings of this study will cover the main areas; demographic characteristics, healthy eating habits, unhealthy eating habits and relation between eating habits and body mass index among nursing students.

Regarding demographic characteristics of the patients; the current study demonstrated that the majority of the study subjects were females. This would be attributed to the fact that the majority of the nursing students in Benha Faculty of Nursing were females while the minority of them were males. These findings agreed with [32], in their study about " Relation between eating habits and a high Body Mass Index among Freshman Students ", found that more than half of the study subjects were female students. As well as[15], in their study about " Influence of dietary habits of University Students on Body Mass Index, found that more than half of the study participants were female students.

Regarding Body Mass Index; results of the current study revealed that, the majority of students were in normal weight category, while about one fourth of them were in overweight category and the remnant were in underweight and obese categories. This would be explained to the fact that. The age of university students is higher than the age of the adolescent students in the other studies, and willingness of nursing students to keep their weight within normal range. These results going in line with the similar studies; [33] and [8], represented that, about half the students were within normal weight, while more than one fourth of them were underweight. As well, [34], explored that the great bulk of the students were of normal weight; more than one-fourth were underweight; and few percentage of them were overweight/obese students.

This is consistent with [28], who stated that, the overall prevalence of normal weight represents the majority of the students, and two fifth of them were overweight and underweight while fewer percentage of them was obese. On the other hand, [35], found that, about two thirds of adolescents belonged to normal and underweight, and the last third of them were obese and overweight. These findings are in line with[24], who found that, almost of students had normal weight but there is a reasonably high occurrence of overweight among the students.

Regarding the relation between students' gender and their BMI; results of the current study demonstrated that, there is no significant statistical difference between male and female subjects related to their BMI among the students. This may be explained as male and female nursing students exhibited similar level of nutritional knowledge and many students in both sexes were mindful about their body weight, in order to stay at a fashionable weight. In agreement with these study findings [36], illustrated that no significant statistical difference between both sex related to their body mass index. This in line with [37], who demonstrated that no differences were observed between the BMI of men and that of women within each group for the control group and overweight group respectively. These findings are inconsistent with [38] and [32], who reported that female subjects integrated in their study had lesser BMI than male subjects based on their self-reported body weight and height records. As well, [39], Showed that elevated percentage of male students were overweight and obese compared to female students, while a greater percentage of females were underweight. 


\section{Unhealthy eating habits:}

Concerning eat fast foods; findings of the current study illustrated that the majority of students regularly eat fast food .These results may be due to the fact that nursing students spend more time within the nursing faculty for receiving theory and practical courses so they likes fast food to conserve their time. On the other hand, students also believed that unhealthier foods in the form of fast food are less expensive than preparing a healthy meal at home. As well as, lack of students' knowledge about importance of eating healthy food and its content. These findings consistent with [40], who stated that students often select fast food due to its palatability, availability and convenience. This agrees with [41]; [42]; [43]; [44]and [45], who reported in their studies that there was higher levels of dietetic consumption among the university students for fast food. Also, [15], found most of the studied sample in Egypt consumed fast food weekly, while in Turkey the majority of participant, sometimes consumed fast food. Contradiction to these studies was by the findings of [46], who reported that only very few number of respondents visited fast food restaurants frequently. Also, [47], found that only less than one quarter of respondents consumed fast food often. In addition, [48], Showed that lower consumption of fast foods by Syrian adolescent students.

Pertaining to eat fatty and frying food; findings of the current study demonstrated that the majority of the students consumed fatty and nearly half of them consumed frying food regularly. This may be related to the pleasant taste of the fried food while the frying method is the favorite cooking method for all people in adolescent phase. This in line with [49], who reported high conservation of fatty foods and fries among the study group. Also, [50], in their study on adolescents found greater fatty food utilization with them. This is consistent with [51], who illustrated that most of the students habitually eating fatty and oily foods. In addition, [25], stated that several students favored fried food. In contrast to these study findings, [47] and [40], stated that majority of subjects reported low consumption of fried food. In agreement to these study findings [15], reported that the fried food has a lot of harmful effects on health.

Concerning dessert food; the current study findings indicated that most of the students demonstrated high conservation of dessert food. This result is supported by[51], who reported that most of the students ate sweetened foods. This confirmed with [15], who showed that the majority of studied groups for all countries devoted desserts daily in Egypt, Saudi Arabia and Turkey. Moreover, [25], reported in their study that most students utilized desserts on a daily basis.

Regarding consumption of fizzy drinks, tea and coffee; the current study findings indicated that great part of the students never and rarely drink fizzy with meals as well as drink coffee after meals, while more than half of them drank tea after meals. This result may be attributed to the pleasant taste of tea and the popularity of this drink among Egyptian people. These results contradicted with [52], who found that fizzy drinks were the preferred snakes among Egyptian students as well during watching TV. This result is supported by [15], who reported that fizzy drinks were the favorite drinks among Egyptian students. In addition, their data referred that the most preferred drink for the greater part of studied sample in Egypt and Turkey were tea, while in Saudi Arabia coffee was the beloved drink for the majority of studied sample. These results are consistent with [25], who stated that, nearly all of students consumed fizzy drinks and most of them often favoring to have a coffee. On the other hand the study of [53], showed that, most of the students drank healthy drinks and fewer of them drank coffee or tea. These results is supported by [54] and [55], who stated that, individuals consuming high amounts of these sugared drinks may cause an increase in their body weight even if they decrease the consumption of other food items.

Regarding eat snakes between meals; the current study findings indicated that the majority of the students ate snakes between meals. This probably due to factors related to changes in adolescents' lifestyle, such as lack of time for eating, influence of the media, and preference for the taste, together with the habit of eating out home and the utilization of increasingly large food portions. The consumption of snacks reported by the adolescents of the present study in replacement of traditional healthy meals leads to a reduction in the consumption of the nourished foods. According to the [56], the low consumption of these foods is one of the main factors associated with disease in the world, because these foods are important sources of fibers, vitamins, and minerals, and also show low calorie content. In their studies, [40] and [57], reported that, the regular conservation of snacks and light meals is an identifiable feature of teenage and university students food habit. Also, According to the results of [53] and [47], all of the university students ate daily snakes. As well, [48] and [8], indicated that the majority of adolescent students consumed snakes between breakfast and lunch as well as between lunch and dinner. This in line with [45] and [25], who reported greater levels of dietary devotion among the university students for snakes. In addition, [15], in his study demonstrated that, the greater part of the students of the three studied samples in Egypt, Saudi Arabia and Turkey were eating snakes.

\section{Healthy eating habits:}

About eat breakfast daily; the current study reported that more than half of the students were not regularly eat breakfast daily. This may be due to most of them from far places than the college and get ride early 
to attend the practical and theoretical lectures, so no sufficient time to take breakfast. Supporting to these study findings, [40] ; [46]; [58] and [59], revealed that meal leaving out; principally breakfast, and diverse weight loss eating behaviors were various unhealthy dietary behaviors showed by Malaysian adolescent girls. This in line with [47], who reported that less than half of study subjects had breakfast daily. This agrees with [51] ; [8] and [60], who noted that most of the study participants didn't eat breakfast. Opposition to these study findings were by [53] and [47], who stated that, less than half of the students beginning the day with a healthy breakfast. Another systematic review concluded that eating breakfast is linked with a decreased risk of overweight and obesity and decline in BMI in children and adolescents [58]. In addition, [8] and [61], noted that greater than half of the total number of respondents ate breakfast.

Concerning eat more vegetables and fruits; results of the current study demonstrated that, the majority of study sample were repeatedly and often eat more fruits and vegetables. These results may be related to that nursing student's shows a satisfactory level of nutritional knowledge during studying nutrition subject in their College. As well, they become more oriented about significance of eating vegetables and fruits in constructing a healthy human body. In agreement with these study findings, [62]; [40]; [53] and [47], pointed out that less than half of participants ate fruits at least three times per week. These results consistent with [8] and [45], who reported that, the great bulk of the students having about five servings of vegetables and fruit daily.

These findings were high in comparison to another studies; a study from Spain demonstrated that between university students in Spain, there were reduced levels of compliance to Nutritional Pyramid of the Spanish Nutrition Society for vegetables and fruits [63].This in line with [50], who discovered that, only a few percentage of the students was found to congregate the fruit and vegetable eating recommendation and less than half were eating only less than one serving of fruit and vegetables daily. A study from China, found about one fourth of participants only consumed vegetables and fruits, [57]. However, another study from Malaysia noted that only the minority of university students devoted vegetables more than three times weekly [26].This finding in agreement with [51] and [64], who concluded that the acceptance of unhealthy eating habits along with college students, mainly with regard to the reduced utilization of fruit and vegetables.

Regarding consumption of dairy foods; encouragement of a sufficient milk intake would be a superior therapeutic approach [65]. While the current study reported that, the majority of students were not regularly eat or drink dairy foods. This result may be related to lack of student knowledge about the importance of regular diary food intake. In agreement with these study findings [8], who reported in their study that the bulk of the study subjects had low daily milk conservation. This result confirmed by [45], who reported that the university students had low levels of dietary compliance for dairy and dairy products. In contrast to these study findings, [63], demonstrated that, there was a greater proportion of university students who pursue the reference of the new Nutritional Pyramid of the Spanish Nutrition Society (SEN) about intake of milk and dairy products. In addition, [25], reported in their study that, the majority of students adhered to milk intake.

Concerning consumption of whole grain foods; the current study reported that, great part of students were not properly consumed whole grain foods. This study results agrees with [63], who reported that, university students in Spain, had little devotion to intake of cereals and legumes. This result is consistent with [66], who noted that higher proportion of undergraduate students in Nigeria were follow minimum number of cereal servings from the suggested number. Moreover, [19], noted that the food products that had fewer adherence were gelatin and cereal bars with elevated dietetic fiber and little fat. On the other hand, [45 ], in their study demonstrated that, among the consumption of university students from cereal and cereal products was at the moderate level.

About eating three meals every day; the current study reported that, the majority of students were not habitually eat three meals daily and keep track of it. This result may be attributed to inadequate time available for the students to eat three meals as they are usually attending theoretical lectures and practical training. This study finding agrees with the results of another study conducted on university students, it was identified that university students usually omitted meals, the mainly skipped meal was lunch, the first reason for skipping meal was not having enough time and the students have unbalanced eating habit[67]. Also, [68] and [51], illustrated that, leaving out of meals was recognized as a common dietary habit along with adolescent students. In addition, [69],reported that, the mainstream of the students were usually omitting meals. As well, [25], reported that ,the majority of students ate two meals. .n contradiction to these results, [62] and [70], reported that the Chinese university students devoted regular meals, and took at least three meals per day. Another study noted that the greater part of Lebanese university students demonstrated regular meals daily [40].This in line with [32] and [47], who reported that more than half of the students were eating three meals per day.

Concerning gender differences regarding eating habits; the current study reveals that there is no significant statistical difference between students gender and their eating habits. This finding may be attributed to that both genders had identical body weight and they strive to follow ideal weight recommendations. In agreement with this study, [71], reported that, in Hong Kong, students' scores on the dietary habits did not vary 
extensively by gender. Also, [72], stated that, there was no facts of a momentous statistical variation between students gender and their dietary habits. This in line with [73], who illustrated that there was no important statistical discrepancy between nutritional habits and students gender. Contradiction to these studies, [74] and [75], reported that a significant difference among male and female Syrian adolescents in their eating habits and lifestyle was recognized. As well, [34], reported that, female students had higher correct eating habits than male students. Moreover, [48], identified a major dissimilarity amongst Syrian adolescents in nutritional habits and lifestyle that involving both genders.

Regarding correlation between students' eating habits and their BMI; Findings of the current study demonstrated that there is no significant statistical correlation between eating habits and BMI among the students. These results may be due to increasing the proportion of adolescents meeting recommended dietary and physical activity guidelines and the nursing students had increased awareness on the importance of their weight control. In agreement with these study results [8] and [35], found that, there is no important statistical correlation between the dietary habits and body mass index of the chosen adolescents. In contrast, a study conducted by [76], in Bangalore to co-relate the dietary habits and body mass index of the adolescents. The finding discovered that there is a co-relation between eating habits and body mass index of the adolescents. The same result documented by [32]. These results are inconsistent with another studies conducted by [50] and [77], who analyzed the sweetened drinks and high fat food conservation, demonstrated a strong statistical alliance between the overweight and obese groups and the eating habit related to those items. Also [78], conduct a study in Turkey and stated that, a negative co-relation between dietary habits and body mass index among students. This is supported by, [28], who indicated that there is a positive association between unhealthy foods with body mass index and an opposite correlation between healthy foods and body mass index. Additionally, a study conducted by [69 ], confirmed that body mass index had affinity to raise as fast foods, soft drink and chips conservation increased and body mass index had propensity to reduce as vegetables, dairy products and fruits utilization increased.

Regarding the distribution of the students according to their eating habits; results of the current study findings illustrated that, the majority of the students in the current study had neutral eating habits. This may be indicated that the students within this study were fluctuated between healthy and unhealthy habits and risky to became deteriorated healthy level. These findings agreed by [79], who noted that the growing of shopping malls, food stores, selling machines and fast food channels have produced an frightening situation for young adults to follow unhealthy eating habits. This in line with [80] and [11], who demonstrated that the complexity to implement a diet adhering with the guidelines is a major problem that involve college students from numerous races and with diverse eating habits. In addition, unhealthy dietary habits is a chief public health apprehension among young adults who practiced transition into university life [81]. During which, they are showing a tension and lack of time [82]. Inconsistently, [35], pointed out that, greater part of the adolescent had healthy eating habits. While on the other study findings, [83] ; [84] and [85], showed that adolescents didn't have healthy dietary habits and denoted that healthy dietary behaviors could be adapted as a result of interference made with teaching in their study. Another study in Saudi Arabia reported a prevalence of unhealthy eating habits among participants[22]. Additionally, [7], found a few number of the students surveyed had essentially healthy eating habits as they did not select healthy foods, such as high-fiber and low-fat foods. As well as, [53] ; [15] and [45], concluded in their studies that the students had considerably unhealthy dietary habits and carried important risks in this respect.

\section{Conclusion And Recommendations}

Most of the nursing students in this study had a neutral eating habits which means that they were practicing healthy eating habits in the same way with unhealthy eating habits. In addition, there was no association between eating habits and body mass index among the study group and there was no significant statistical difference between male and female students regarding their body mass index as well as their eating habits. Sufficient knowledge about healthy food assortment and food safety can be prejudice factors for enhancing eating habits and implementing a good healthy diet, so motivations required for nursing students to assume healthy eating habits. Education programs can be provided to students to increase their awareness about healthy food and encouraging them to practice healthy eating habits. Posters and pamphlets on healthy eating habits can be exhibited in the lecture halls to create awareness among students. Conducting regular campaigns to raise attentiveness about healthy eating and encourage students to adopt healthier lifestyles. The University could also make healthy meal packs and food supplements available to students at affordable prices. Moreover further studies can be carried out to explore factors affecting eating habits and the relation between eating habits and academic achievement among university students. 


\section{References}

[1]. Centers for Disease Control and Prevention (CDC) (2012). Healthy People 2020.Availablefrom:URL: http://www.healthypeople.gov/2020/default.aspx

[2]. Kremmyda, L.S., Papadaki, A., Hondros, G., Kapsokefalou, M. and Scott, J.A. (2008). Differentiating between the effect of rapid dietary acculturation and the effect of living away from home for the first time, on the diets of Greek students studying in Glasgow. Appetite; 50: 455-463.

[3]. Manu, R. and Krishna R.(2011). Obesity in children \& adolescents. Indian Journal of Medicine;132:598-607.

[4]. Adole, A. (2014). Assessment of Breakfast Eating Habits and its Association with Cognitive Performance of Early Adolescents. Southern Ethiopia. JFNS; 2:130.

[5]. Shriver, L.H., Harrist, A.W., Hubbs-Tait, L., Topham, G., Page, M.,and Barrett, A.(2011). Weight Status, Physical Activity, and Fitness among 3rd Grade Rural Children. J Sch. Health; 81(9):536-544.

[6]. Hoyland, A., Dye, L. and Lawton, C.L. (2009). A systematic review of the effect of breakfast on the cognitive performance of children and adolescents. Nutr Res Rev; 22: 220-243.

[7]. Silveira, B.M., Kliemann, N., Silva, D.P., Colussi, C.F. and Proença, R.P.C. (2013). Availability and Price of Food Products with and without Trans Fatty Acids in Food Stores around Elementary Schools in Low- and Medium-Income Neighborhoods. Ecol Food Nutr; 52: 63-75.

[8]. Al-Muammar, M.N., El-Shafie, M. and Feroze S.(2014). Association between dietary habits and body mass index of adolescent females in intermediate schools in Riyadh, Saudi Arabia. EMHJ; (20):1.

[9]. Papadaki, A., Hondros, G., Scott, J.A. and Kapsokefalou, M. (2007). Eating habits of University students living at, or away from home in Greece. Appetite; 49: 169-176.

[10]. Deshpande,S., Basil, M.D. \&Basil, D.Z.(2009). Factors influencing healthy eating habits among college students: An application of the Health Belief Model. Health Marketing Quarterly; 26(2): 145-164.

[11]. Baldini, M., Pasqui, F., Bordoni, A.and Maranesi, M. (2009). Is the Mediterranean lifestyle still a reality? Evaluation of food consumption and energy expenditure in Italian and Spanish university students. Public Health Nutr; 12(2):148-55.

[12]. Wengreen, H.J., Moncur, C. (2009). Change in diet, physical activity, and body weight among young-adults during the transition from high school to college. Nutr J; 8:32.

[13]. Azadbakht, L., Haghighatdoost, F., Feizi, A., Esmaillzadeh, A. (2013). Breakfast eating pattern and its association with dietary quality indices and anthropometric measurements in young women in Isfahan. Nutrition; 29(2):420-5.

[14]. Alsheikh-Ali, A.A., Omar, M.I., Raal, F.J., Rashed, W., Hamoui, O., Kane, A., et al. (2014). Cardiovascular risk factor burden in Africa and the middle east: the Africa middle east cardiovascular epidemiological (ACE) study. PLoS One; 9(8): 102-30.

[15]. El Sayed, H.H., El-Shafei, M.M. and Toprak, L.(2015). Influence of dietary habits of university students on body mass index (BMI) (a comparative study among Egypt and Saudi Arabia and turkey). Firat University Journal of Social Science; 25(2): 315-328.

[16]. Reed,.D.(2014).Healthy Eating for Healthy Nurses: Nutrition Basics to Promote Health for Nurses and Patients. The Online Journal of Issues in Nursing;19(3).

[17]. Bjerrum, M., Tewes, M. and Pedersen, P. (2012). Nurses' self-reported knowledge about and attitude to nutrition - before and after a training programme. Scandinavian Journal of Caring Sciences; 26(1): 81-9.

[18]. Ilmonen, J., Isolauri, E. and Laitinen, K. (2012). Nutrition education and counseling practices in mother and child health clinics: study amongst nurses. Journal of Clinical Nursing; 21(19/20): 2985-94.

[19]. Alejandra, N.M., Paula, C.M. and Patricia, A.M.(2016). Study of Nutrition Habits inPrimary School Students. J Clin Nutr Diet; 2:4.

[20]. Arata, A., Battini, V., Chiorri, C. and Masini, B.(2010). An exploratory survey of eating behavior patterns in adolescent students. Eat Weight Disord;15:200-7.

[21]. Deliens, T., Clarys, P., De Bourdeaudhuij, I. and Deforche, B.(2014). Determinants of eating behaviour in university students: a qualitative study using focus group discussions. BMC Public Health; 18(14):53.

[22]. Al Qauhiz NM.(2010). Obesity among Saudi Female University Students: Dietary Habits and Health Behaviors. Journal of the Egypt Public Health Assoc; 85(1-2):45-59.

[23]. Abdel-Megeid, F.Y., Abdalrahem, H.M. and El-Fetouh, A.M.(2011). Unhealthy nutritional habits in university students are a risk factor for cardiovascular diseases. Saudi Med J; 32(6):621-7.

[24]. Waweru,W.R. and Marete, O.T.(2016). Estimation of relationship between eating habits and body mass index of students in Mount Kenya University, Rwanda. Int J Community Med Public Health; 3(8): 2344-2354.

[25]. Platania, M., Rapisarda, P. and Rizzo, M.(2016). Food and health habits of university students. Relationship to food consumption behavior. International Food Research Journal; 23(3): 1239-1247.

[26]. Gan, W.Y., Mohd, N.M., Zalilah, M.S. and Hazizi, A.S.(2011). Differences in eating behaviours, dietary intake and body weight status between male and female Malaysianuniversity students. Malays J Nutr;17(2):213-28.

[27]. Adolphus, K., Lawton, C.L. and Dye, L.(2013). Impact of breakfast on academic performance, cognitive performance and behavior in school children. Front Hum Neurosci; 8(7):425.

[28]. Hemati,A., Moghadasi, M. and Azizi, F.(2014). Association among lifestyle status and body mass index in Yasuj adolescents. Int.J.Curr.Res.Aca.Rev; (8):19-24.

[29]. Kann, L., McManus, T., Harris, W.A., et al.(2016). Youth Risk Behavior Surveillance-United States, 2015. MMWR Surveill Summ; 65:1.

[30]. World Health Organization (WHO) (2016). Global health observatory data: obesity and overweight fact sheet.31-Payne, K.F.(2008). A comparative study of dietary habits among College students at-risk and not-at-risk for eating disorders and how such habits compare to the dietary guidelines. Thesis Dissertation for master degree. Faculty of Virginia Polytechnic Institute and State University.

[31]. Gunes,F. E., Bekiroglu, N., Imeryuz, N. and Agirbasli, M.(2012): Relation between Eating Habits and a High Body Mass Index among Freshman Students: A Cross-Sectional Study, Journal of the American College of Nutrition; 31(3): 167-174.

[32]. Nur Syuhada Zofiran, M. J., Kartini, I., Siti Sabariah, B. and Ajau, D.(2011). The relationship between eating behaviours, body image and BMI status among adolescence age 13 to 17 years in Meru, Klang, Malaysia. Am. J. Food. Nutr;1(4): 185-192.

[33]. Ayranci, U.1., Erenoglu, N. and Son, O.(2010). Eating habits, lifestyle factors, and body weight status among Turkish private educational institution students. Nutrition; 26(7-8):772-8.

[34]. Benazeera, U.J.(2014). Association between eating habits and body mass index (bmi) of adolescents. Journal of Medical Science and Public Health; 3(8).

[35]. Nakamura,S., Jeong, B., Kim, S. and Moon, S.K,(2007) "Present States and Problems of Food Intake and Nutrition in Japan and Korea," Journal of the Faculty of Agriculture-Shinshu University; 43(1-2): 9-15.

[36]. Santamaría, A.R., Vázquez, I.A., Caballero, D.P. and Rodríguez, C.F. (2009). Eating habits and attitudes and their relationship with Body Mass Index (BMI). Eur. J. Psychiat; 23(4): 214-224. 
[37]. Farajian, P., Risvas, G., Karasouli, K., Pounis, G.D., Kastorini, C.M., Panagiotakos, D.B., et al.(2011). Very high childhood obesity prevalence and low adherence rates to the Mediterranean diet in Greek children: the GRECO study. Atherosclerosis; 217(2):525-30.

[38]. Salameh, P., Jomaa, L., Issa, C., Farhat, G., Salamé, J., Zeidan, N. and Baldi, I.(2014).Assessment of dietary intake patterns and their correlates among university students in Lebanon. Front Public Health; 2: 185.

[39]. Yahia. N., Achkar, A., Abdallah, A. and Rizk, S.(2008). Eating habits and obesity among Lebanese university students. Nutr J;7(32).

[40]. Alizadeh, M. and Ghabili, K.(2008). Health related lifestyle among the Iranian medical students. Res Biol Sci; 3(1):4-9.

[41]. Moy, F.M., Johari, S., Ismail, Y., Mahad, R. and Tie, F.H.(2009). Wan Ismail WMA. Breakfast skipping and its associated factors among undergraduates in a public university in Kuala Lumpur. Mal J Nutr;15(2):165-174.

[42]. Gharib, N. and Rasheed, P. (2011). Energy and macronutrient intake and dietary patterns among school children in Bahrain: a crosssectional study. Nutrition Journal; 10: 62

[43]. Al-Hazzaa, H.M., Abahussain, N.A., Al-Sobayel, H.I., Qahwaji, D.M. and Musaiger, A.O.(2011). Physical activity, sedentary behavior and dietary habits among Saudi adolescents relative to age, gender and region. International Journal of Behavioral Nutrition Physical Activity; 8: 140 .

[44]. El Ansari, W., Suominen, S. and Samara, A.(2015). Eating habits and dietary intake: is adherence to dietary guidelines associated with importance of healthy eating among undergraduate university students in finland? Cent Eur J Public Health; 23 (4): $306-313$.

[45]. Chin, Y.S. and Nasir, M.T. (2009). Eating behaviours among female adolescents in Kuantan district, Pahang, Malaysia, Pakistan. J Nutr; 8(4): 425-432.

[46]. Qureshi, A.M., Al-abed, A.A., Rizal, A.M. and Aljunid, S.M.(2012). Social and psychological factors affecting eating habits among university students in a Malaysian medical school: a cross-sectional study. Nutr J; (11): 48 .

[47]. Musaiger, A.O. and Kalam, F.(2014). Dietary habits and lifestyle among adolescents in Damascus, Syria. Annals of Agricultural and Environmental Medicine ; 21(2): 416-419.

[48]. Skemiene, L., Ustinaviciene, R., Piesine, L. and Radisauskas, R.(2007). Peculiarities of medical students' nutrition. Medicina;43(2):14552.

[49]. Sidoti,E., Mangiaracina ,P., Paolini, G. and Tringali, G.(2009). Body Mass Index, family lifestyle, physical activity and eating behavior on a sample of primary school students in a small town of Western Sicily. IJPH; 6(3):205-217.

[50]. Onyiriuka, A.N., Ibeawuchi, A.N. and Onyiriuka, R.C.(2013). Assessment of eating habits among adolescent Nigerian urban secondary schoolgirls. Sri Lanka Journal of Child Health; 42(1): 20-26.

[51]. Mahfouz, E.M., Sadek, R.R. and Abdel-Latief, W.M.(2014): The Role Of Dietary And Lifestyle Factors In The Development Of Colorectal Cancer: Case Control Study In Minia, Egypt. Cent Eur J Public Health 2014; 22 (4): 215-222.

[52]. Cefai, C. and Camilleri, L.(2011).The dietary habits of Maltese university students. Malta Medical Journal; (23): 2.

[53]. Malik, V.S., Schulze, M.B. and Hu, F.B.(2006). Intake of sugar-sweetened beverages and weight gain: a systematic review. Am J Clin Nutr; 84:274-288.

[54]. Boo, N.Y., Chia, G.J., Wong, L.C., Chew, R.M., Chong, W. and Loo, R.C.(2010). The prevalence of obesity among clinical students in a Malaysian medical school. Singapore Med J; 51:126-132.

[55]. World Health Organization (WHO)(2010). The world health report 2010: reducing risks, promoting healthy life. Geneva.

[56]. Musaiger, A.O., Bader, Z., Al-Roomi, K. and D’Souza, R.(2011). Dietary and lifestyle habits amongst adolescents in Bahrain. Food \& Nutrition Research;55:7122.

[57]. Szajewska, H. \& Ruszczynski, M.(2010). Systematic review demonstrating that breakfast consumption influences body weight outcomes in children and adolescents in Europe. Critical Review in Food Science and Nutrition; 50: 113-119.

[58]. Akici, S.Y., Yagmur, C., Parlak, E. and Kurdak, S.S.(2011). Evaluating the Nutritional Status and Eating Habits of Adolescent Female Basketball Team Players J Sports Sci; 3(2):62-9.

[59]. Kim, S.Y., Sim, S., Park, B., Kong, I.G., Kim, J.H., et al. (2016). Dietary Habits Are Associated With School Performance in Adolescents. Medicine (Baltimore); 95: 3096.

[60]. Mentes,E., Mendes, B. and Karacabey, K.(2014). The investigation of physical activity levels and eating habits in adolescents. European Journal of Experimental Biology; 4(1): 693-698.

[61]. Sakamaki, R., Toyama, K., Amamoto, R., Liu, C.J. and Shinfuku, N.(2005). Nutritional knowledge, food habits and health attitude of Chinese university students: a cross sectional study. Nutr J;4(4).

[62]. Bayona-Marzo, I., Navas-Cámara, F.J., Fernández de Santiago, F.J., Mingo- Gómez, T., de la Fuente-Sanz, M.A. and Cacho del Amo, A.(2007). Eating habits in physical therapy students(In Spanish). Nutr Hosp;22(5):573-7.

[63]. Lupi,S., Bagordo,F., Stefanati, A., Grassi, T., Piccinni, L., Bergamini, M..and De Donno, A.(2015). Assessment of lifestyle and eating habits among undergraduate students in northern Italy. Ann Ist Super Sanità;51 (2): 154-161.

[64]. Naik,S., Bhide,V., Babhulkar, A., Mahalle,N., Parab,S., Thakre, R. and Kulkarni, M. (2013):Daily milk intake improves vitamin B-12 status in young vegetarian Indians: an intervention trial. Nutrition Journal, 12:136.

[65]. Otemuyiwa, I.O. and Adewusi, S.R.(2012). Food choice and meal consumption pattern among undergraduate students in two universities in Southwestern Nigeria. Nutr Health;21(4):233-45.

[66]. Yilmaz, E., and Ozkan, S. (2007).Investigation of the Eating Habits of College Students, V. Primary Health Care Symposium, Manisa.

[67]. Montazerfar, F., Karajibani, M. and Dashipour, A.R.(2012). Evaluation of dietary intake and food patterns of adolescent girls in Sistan and Baluchistan Province, Iran. Journal of Functional Foods in Health and Disease; 2(3):62-71.

[68]. Solomon, A., Mbat, E., Medavarapu, S., Faletil,O. and Otohinoyi, D.(2016). Feeding Habits and its Impact on Concentration and Attentiveness among Medical Students in Dominica. iMedPub Journals;8(5):9.

[69]. Karasu, Ö.(2006). With boarding and non-boarding of High School Students and Assessing Nutritional Information, Gazi University, Institute of Education Sciences, Family Economics and Nutrition Education field of study, Master Thesis; Ankara.

[70]. Lee, R.L. and Loke, A.J.(2005). Health-promoting behaviors and psychosocial well- being of university students in Hong Kong. Public Health Nurs;22(3):209-20.

[71]. Cheung, K. P.C.H., Ip, P.L.S., Lam, S.T. and Bibby, H. (2007). A study on body weight perception and weight control behaviors among adolescents in Hong Kong. Hong Kong Med Journal; 13: 16-21.

[72]. Monir, Z. M., Khalifa, A.G., Hassaballa, F., Tawfeek, S., Abdelmonem, M., Shady, M.A. and Mansour, M. (2010). Eating Behavior and Problems in Egyptian Adolescents; Relation to Dietary Intake. Journal of American Science; 6(12): 1145-1159.

[73]. Tirodimos, I., Georgouvia, I., Savvala, T.N., Karanika, E. and Noukari, D.(2009). Healthy lifestyle habits among Greek university students: differences by sex and faculty of study. East Mediterr Health J;15(3):722-8.

[74]. Santos, S.S.(2009). Food habits and food choice motives among university students settled in London: The role of gender and culture. Research Project; Porto University.

[75]. Najagaraja, GJ. (2007). Co-relation study to assess the eating habits and body mass index of the adolescents from school and colleges [M.sc thesis]. Rajiv Gandhi Health Science; Karnataka. 
[76]. Polikandrioti, M., Kotronoulas, G., Liveri, D., Giovaso, S., Varelis, G. and Kyritsi, E.(2009). Body mass index, central obesity, and dietary patterns in a group of young adult men. Health Science journal; 3(1):54-63.

[77]. Bąk-Sosnowskam M. and Skrzypulec, V.(2012). Eating habits and physical activity of adolescents in Katowice--the teenagers' declarations vs. their parents' beliefs. J Clin Nurs; 21:2461-8.

[78]. King, K.A., Mohl, K., Bernard, A.L. and Vidourek, R.A.(2007). Does involvement in healthy eating among university students differ based on exercise status and reasons for exercise? Californian Journal of Health Promotion;5(3):106-119.

[79]. Charanleen (2008). Eating habits of the young generation. MBA thesis; Pune University.

[80]. Nelson, M.C., Story, M., Larson, N.I., Neumark-Sztainer, D. and Lytle, L.A.(2008). Emerging adulthood and college-aged youth: An overlooked age for weight-related behavior change. Obes;16(10):2205-2211.

[81]. Rubina, A., Shoukat, S., Raza, R., Shiekh, M.M., Rashid, Q., Siddique, M.S., Panju, S., Raza, H., Chaudhry, S. and Kadir, M.(2009). Knowledge and practice of healthy lifestyle and dietary habits in medical and non-medical students of Karachi, Pakistan. J Pak Med Assoc;59(9):650-655.

[82]. Demirezen, E. and Cosansu, G. (2005). Adolescent Eating Habits in Student Assessment, Istanbul U. Florence Nightingale HYO, Public health nursing; Istanbul.

[83]. Ozmen, D., Cetinkaya Aynur, C., Ergin. D., Sen, N., and Erbay Dundar, P., (2007).The association of self-esteem, depression and body satisfaction with obesity among Turkish adolescents.TAF Preventive Medicine Bulletin; 6(2):98-10, 2007.

[84]. Akman, M., Akan, H., Izbirak, G., Tanriover, O., Tilev, S.M., Yıldız, A., Tektaş S., Vitrinel A. and Hayranm O.(2010). Eating Patterns of Turkish Adolescents Compared With Recommendations Eating Patterns of Turkish Adolescents Compared With Recommendations. Nutrition Journal; 9:67. 